\title{
The Effect of Photovoltaic Panels on the Rooftop Temperature in the EnergyPlus Simulation Environment
}

\author{
Changhai Peng ${ }^{1,2,3}$ and Jianqiang Yang ${ }^{1}$ \\ ${ }^{1}$ School of Architecture, Southeast University, Nanjing 210096, China \\ ${ }^{2}$ Key Laboratory of Urban and Architectural Heritage Conservation (Southeast University), Ministry of Education, \\ Nanjing 210096, China \\ ${ }^{3}$ College of Engineering and Applied Science, University of Colorado Denver, Denver, CO 80217, USA
}

Correspondence should be addressed to Changhai Peng; pengchanghai@foxmail.com

Received 15 October 2015; Revised 1 January 2016; Accepted 18 January 2016

Academic Editor: Ahmad Umar

Copyright (C) 2016 C. Peng and J. Yang. This is an open access article distributed under the Creative Commons Attribution License, which permits unrestricted use, distribution, and reproduction in any medium, provided the original work is properly cited.

In this paper, the effects that photovoltaic (PV) panels have on the rooftop temperature in the EnergyPlus simulation environment were investigated for the following cases: with and without PV panels, with and without exposure to sunlight, and using roof materials with different thermal conductivities and for different climatic zones. The results demonstrate that heat transfer by convection, radiation, and conduction in the air gaps between PV panels and the building envelope can be simulated in the EnergyPlus environment when these air gaps are in the "air conditioning zone." Nevertheless, in most cases, particularly on the rooftop, the air gaps between the PV panels and the building envelope cannot be set as the "air conditioning zone." Therefore, in this case, none of the EnergyPlus models are appropriate to simulate the effect that PV panels have on the rooftop temperature. However, all the terms of the Heat Balance Model, including the absorbed direct and diffuse solar radiation, net long-wave radiation with the air and surroundings, convective exchange with the outside air, and conduction flux in or out of the surface, can still be used to calculate the temperature and heat flux within the BIPV's air gap.

\section{Introduction}

EnergyPlus is a whole-building energy simulation program that engineers, architects, and researchers use to model energy and water use in buildings. Modeling the performance of a building with EnergyPlus enables building professionals to optimize the building design so that the building uses less energy and water. The Photovoltaics.f90 module includes three different models, which are referred to as "simple," "equivalent one-diode," and "Sandia." The choice of the model determines the mathematical models (and input data) used to determine the energy produced by the solar/electric conversion panels. All of the photovoltaic (PV) module models share the same models for predicting the incident solar radiation for the solar thermal calculations. These models are described in the Climate, Sky, and Solar/Shading Calculations section [1].

Currently, these three are the most commonly used models to calculate the electricity output generated from PV modules and the electricity and hot water generated from photovoltaic/thermal (PV/T) collectors. For example, Pless et al. [2] used DOE-2.1E to develop and model a new building in the Teterboro Airport for energy efficient predesign and, subsequently, conducted extensive whole-building annual energy simulations using EnergyPlus. Ordenes et al. [3] analyzed the potential of seven building integrated photovoltaic (BIPV) technologies implemented in a residential prototype in three different cities in Brazil via a simulation using EnergyPlus. Hachem et al. [4] used EnergyPlus to simulate 26 configurations consisting of combinations of parameter values. Zogou and Stapountzis [5] examined an improved concept for incorporating PV modules into the southern facades of an office building. Gang et al. [6] studied the annual electricity and hot water outputs generated from heat-pipe PV/T (HP-PV/T) systems in Hong Kong, Lhasa, and Beijing, China. Mandalaki et al. [7, 8] assessed the PV electricity generation efficiency of fixed shading devices using EnergyPlus. Ng et al. [9] examined six commercially available 
semi-transparent BIPV windows-four single-glazed and two double-glazed windows-using EnergyPlus. Hsieh et al. [10] analyzed the PV potential of rooftops and vertical facades in an area of the West Central District of Tainan City, a rich insolation area in Taiwan.

Few studies have considered the impact that rooftop solar PV modules have on building cooling loads. ITRON Inc. [11] found that after (nonbuilding integrated) PV installation, the amount of energy expended on air conditioning used on high-cooling-degree-day conditions decreased compared to a reference sample. A one-degree increase in the daily average temperature in San Diego Gas \& Electric (SDG\&E) territory caused post-PV installed households with air conditioning to use $0.501 \mathrm{kWh}$ less energy per day. Supporting this finding, a conduction model indicated a $65 \%$ reduction in the cooling load experienced through a roof with installed PV panels compared to a conventional roof with a thermal resistance of R16 [12]. Wang et al. [13] modeled the one-dimensional transient heat transfer for a summer and winter day in China using four setups: ventilated air gap BIPV, nonventilated (closed) air gap BIPV, close mount BIPV, and conventional R8 roof with a solar absorbance of 0.9 . In the summer, the daily heat gain and peak cooling load decreased by approximately $50 \%$ for the ventilated air gap BIPV compared to conventional roofing, whereas the heat gains and peak cooling loads for the closed air gap and close-roof mounted BIPV were within 10\% of that experienced by a normal roof. The PV performance was $6 \%$ greater for the air gap case than for the nonventilated air gap and close-roof mounted cases. In the winter, the ventilated air gap and close mount decreased the peak heating load and heat losses by 5 to $10 \%$, whereas the nonventilated air gap decreased the peak heating load and heat losses by $20 \%$. The PV generation performance for all the modules was within $2 \%$ in the winter. Tian et al. [14] found a significant reduction in the BIPV roof surface temperatures compared to a conventional roof with an albedo of 0.30 and a thermal resistance of $1.33 \mathrm{~K} \mathrm{~m}^{2} \mathrm{~W}^{-1}$.

The indirect benefits of rooftop PV systems used for building insulation were quantified through measurements and modeling. Measurements of the thermal conditions over a roof profile on a building partially covered by PV panels were conducted in San Diego, California [15]. Thermal infrared imagery on a clear April day demonstrated that the daytime ceiling temperatures beneath the PV arrays were as much as $2.5 \mathrm{~K}$ cooler compared to those beneath the exposed roof. Heat flux modeling showed a significant reduction in the daytime roof heat flux beneath the PV array. At night, the conditions reversed, and the ceiling beneath the PV arrays was warmer than the exposed roof, demonstrating the insulating properties of installed PV systems. The simulations showed no benefit (but also no disadvantage) associated with PV systems being installed on the roof in terms of the annual heating load. However, a $5.9 \mathrm{kWhm}^{-2}$ (or $38 \%$ ) reduction in the annual cooling load was observed. The reduced daily variability in the rooftop surface temperature beneath the PV array reduces the thermal stresses on the roof and leads to energy savings and/or human comfort benefits, particularly for rooftop PV modules installed on older warehouse buildings.
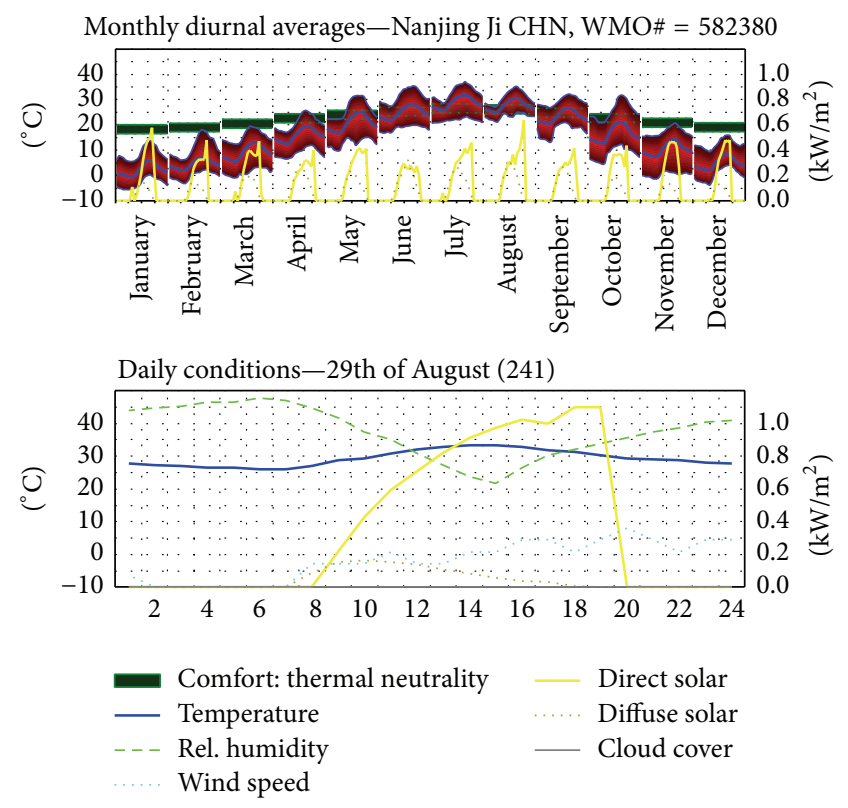

Figure 1: Annual meteorological data for Nanjing.

In this paper, the effects of PV panels on rooftop temperatures in the EnergyPlus simulation environment were investigated for the following cases: with and without PV panels, with and without exposure to sunlight, and using roof materials with different thermal conductivities and for different climatic zones.

\section{Climate}

Nanjing is located at geographical coordinates $32^{\circ} \mathrm{N}$ and $118.8^{\circ} \mathrm{E}$. The city has a typical climate with hot summers and cold winters. Nanjing's climatic characteristics are as follows: during the cold winter months (January and February), the temperature is the lowest and the wind speed is relatively high. During the hot summer months (July and August), the temperature is the highest and the wind speed is relatively slow. The annual direct horizontal solar radiation in Nanjing is well distributed, and the city has relatively abundant solar energy resources. Figure 1 shows the annual meteorological data for Nanjing (source: EnergyPlus).

\section{Model of a BIPV House}

The south-facing model house considered in this work had a building area of $94.4 \mathrm{~m}^{2}$. The dimensions of the house were length: $11.7 \mathrm{~m}$, width: $7.2 \mathrm{~m}$, and height: $7.3 \mathrm{~m}$. Table 1 lists the overall heat-transfer coefficients for the building envelope. The entire house was defined as one thermal area, that is, one air-conditioned area. The room temperature of the house was set at $18^{\circ} \mathrm{C}$ in the winter and $26^{\circ} \mathrm{C}$ in the summer. The air change rate was 1.0 time/h when the heat or air conditioning was on. Figure 2 shows the BIPV house model without shading. The Sandia model was used to predict the 
TABLE 1: Overall heat-transfer coefficients for the BIPV house.

\begin{tabular}{|c|c|c|}
\hline Structure & Main materials (from outside to inside) & Overall heat-transfer coefficient $K\left(\mathrm{~W} /\left(\mathrm{m}^{2} \cdot \mathrm{K}\right)\right)$ \\
\hline \multirow{3}{*}{ Exterior walls } & Concrete panel & \multirow{3}{*}{0.8} \\
\hline & Fiberglass insulation & \\
\hline & Dry wall & \\
\hline \multirow{3}{*}{ Roof } & Concrete panel & \multirow{3}{*}{0.5} \\
\hline & Plastic benzoic (XPS) board & \\
\hline & Dry wall & \\
\hline \multirow{3}{*}{ Floor } & Wooden floor & \multirow{3}{*}{1.0} \\
\hline & Fiberglass insulation & \\
\hline & Wooden floor & \\
\hline \multirow{2}{*}{ Windows } & 6 clear +12 argon $(\mathrm{Ar})+6$ Low-E & \multirow{2}{*}{2.3} \\
\hline & Glass-fiber reinforced polyurethane (GRPU) door and window profile & \\
\hline Door & Solid wood & 2.0 \\
\hline
\end{tabular}

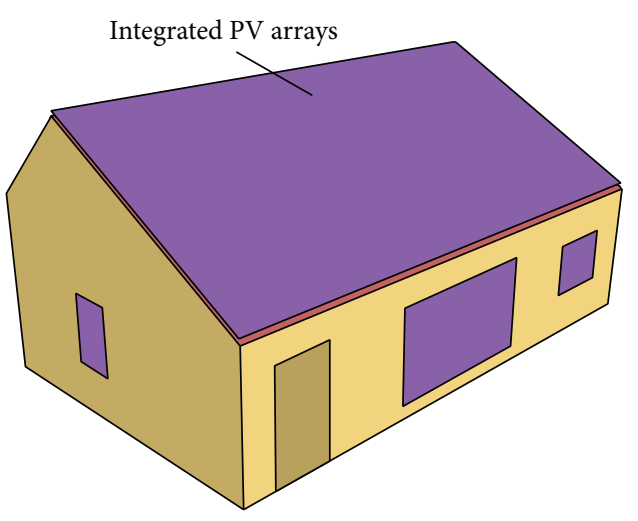

FIGURE 2: Model of the BIPV house.

surface temperature of the roof (the reason for this selection is described in Section 8).

\section{House without PV Panels}

4.1. House Not Exposed to Sunlight. For simplicity, the house with PV panels is referred to as the "BIPV house," and the house without PV panels is referred to as the "regular house." Figure 3 shows the temperature measurement points on the south-facing roof of the regular house when it was not exposed to sunlight. Figure 4 shows the simulated inner and outer surface temperatures for the roof of the regular house.

Figure 4 shows that when the regular house was not exposed to sunlight, the outer surface temperature of the roof of the regular house (measurement point 1 in Figure 3) was lower than the outdoor dry-bulb temperature (measurement point 3 in Figure 3) over the year.

4.2. House Exposed to Sunlight. Figure 5 shows the scenario in which the regular house was exposed to sunlight, and Figure 6 shows the simulation results. When the regular house was exposed to sunlight (Figure 6(a)), the outer surface temperature of the south-facing gable roof (measurement point 1 in Figure 5) was always higher than the outdoor

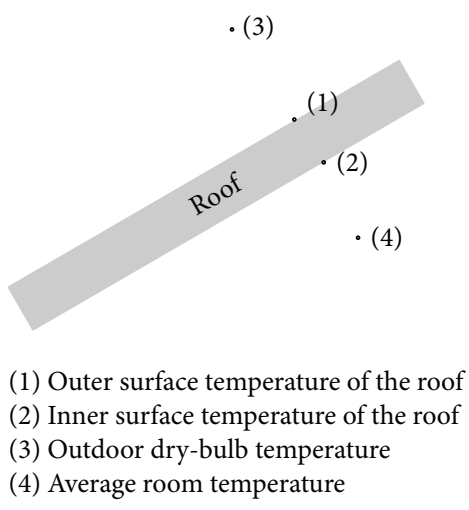

FIGURE 3: Temperature measurement points for the regular house when it was not exposed to sunlight.

dry-bulb temperature (measurement point 3 in Figure 5). Figure 6(b) shows that the outer surface temperature (measurement point 1 in Figure 5) was considerably higher than the outdoor dry-bulb temperature (measurement point 3 in Figure 5) when the south-facing gable roof of the regular house was exposed to solar radiation during the daytime. However, the outer surface temperature was lower than the outdoor dry-bulb temperature during the night. The simulated results were in agreement with the actual situations.

\section{House with PV Panels}

Generally, PV panels are always kept separate from the roof to cool the PV panels and ensure that they generate power under normal conditions, as shown in Figure 7. For this reason, different roof materials thermal conductivities were simultaneously studied, including zero, normal, and infinite thermal conductivities.

5.1. Roof Thermal Insulation Materials with a Zero Thermal Conductivity. Assuming the thermal conductivity of the roof thermal insulation materials was 0 (i.e., the outer surface of the roof was not affected by the indoor thermal environment), 


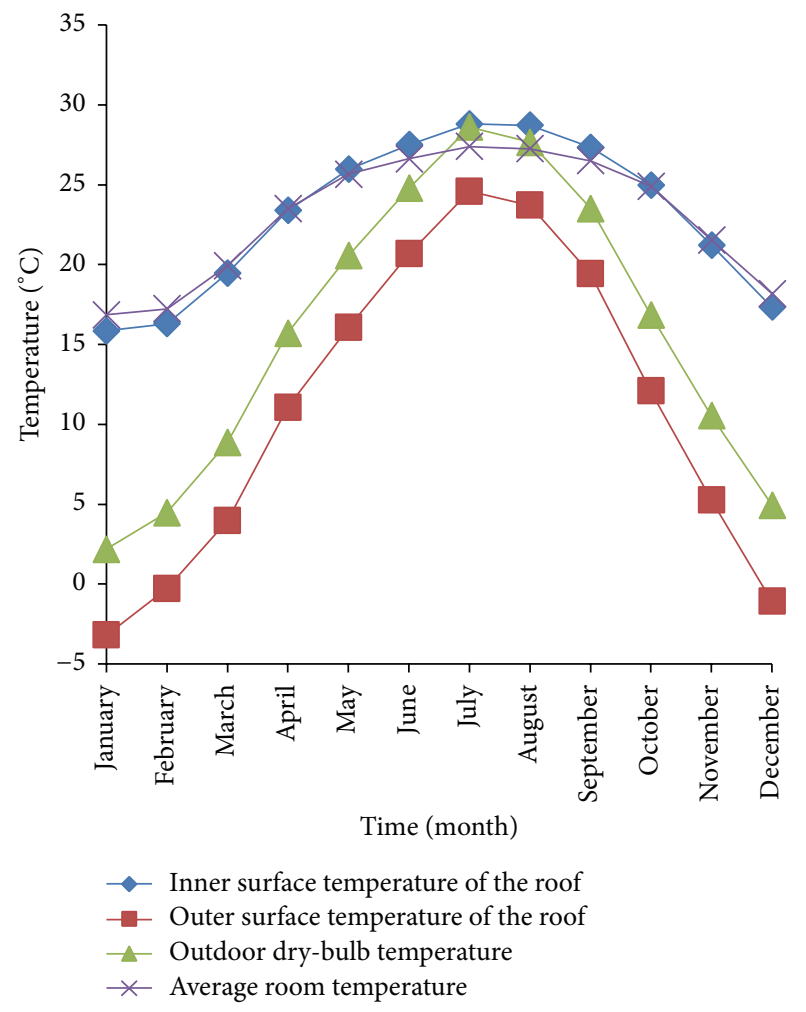

(a) Annual inner and outer surface temperatures for the regular house when it was not exposed to sunlight

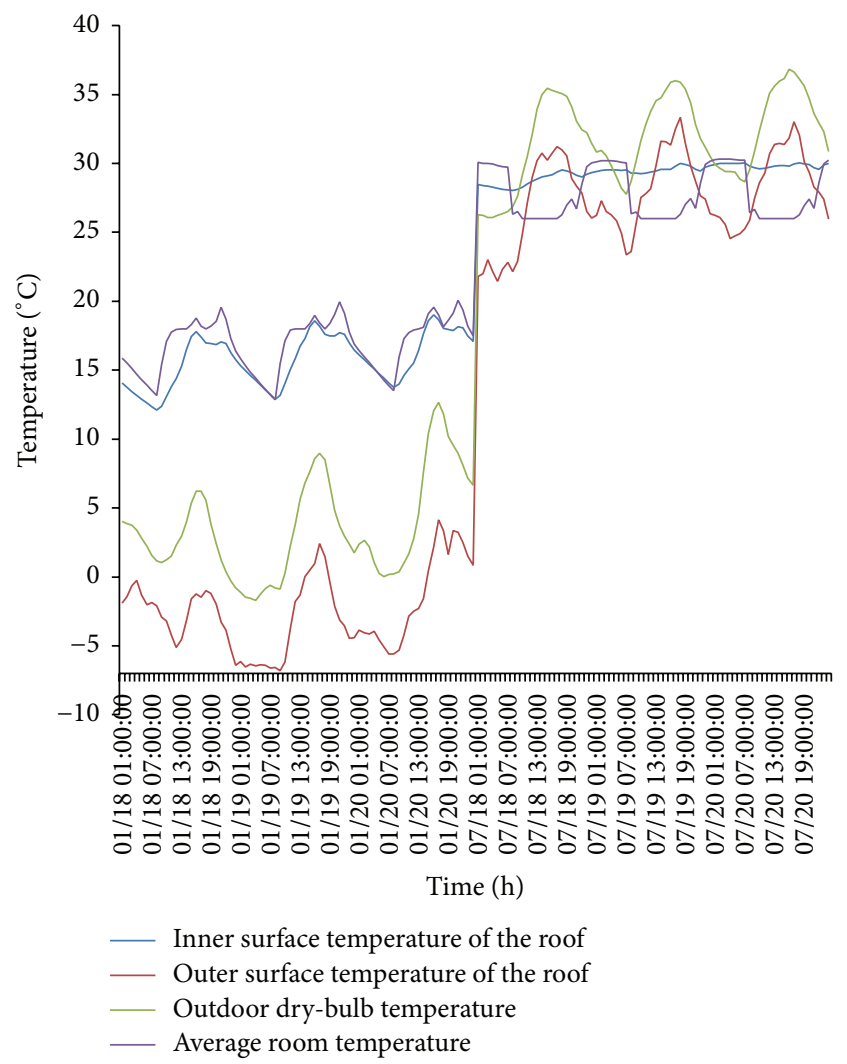

(b) Inner and outer surface temperatures for the regular house when it was not exposed to sunlight over a period of time during the winter and summer

FIGURE 4: Simulated inner and outer surface temperatures for the regular house when it was not exposed to sunlight.

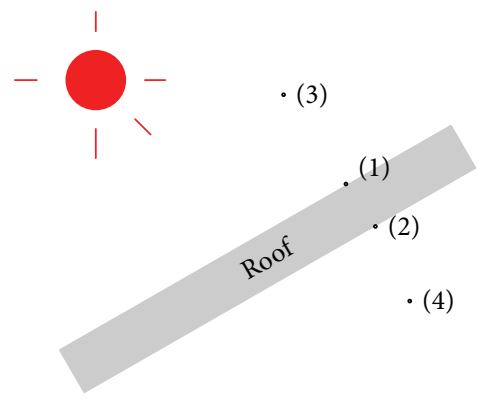

(1) Outer surface temperature of the roof

(2) Inner surface temperature of the roof

(3) Outdoor dry-bulb temperature

(4) Average room temperature

FIGURE 5: Temperature measurement points on the regular house under sunlight.

the outer surface temperature of the roof and the outdoor dry-bulb temperature were compared. Figure 7 shows the inner and outer surface temperatures for the integrated PV array-covered roof. Figure 8 shows the simulated inner and outer surface temperatures for the integrated PV arraycovered roof when the thermal conductivity $K=0$.
Figure 8 shows that when $K=0$, the outer surface temperature of the south-facing integrated PV array-covered gable roof (measurement point 1 in Figure 7) was always lower than the outdoor dry-bulb temperature (measurement point 3 in Figure 7). This result demonstrated that the models could not accurately simulate the effects of thermal radiation from the back of the PV panels.

\subsection{Roof Thermal Insulation Materials with a Normal Thermal} Conductivity. Figure 9 shows the simulated inner and outer surface temperatures for an integrated PV array-covered roof when the thermal conductivity of the roof thermal insulation materials was a normal value. There was a relatively large difference between the inner and outer surface temperatures for this roof in cold winter climate conditions (Figure 9). The temperature difference became relatively small for hot summer climate conditions, although the outer surface temperature remained lower than the inner surface temperature. When air conditioning was used normally, the average room temperature and inner surface temperature of the roof fluctuated over the year. The simulated results were largely in agreement with actual values. However, the outer surface temperature of the south-facing integrated PV array-covered gable roof (measurement point 1 in Figure 7) was always lower than the outdoor dry-bulb temperature (measurement 


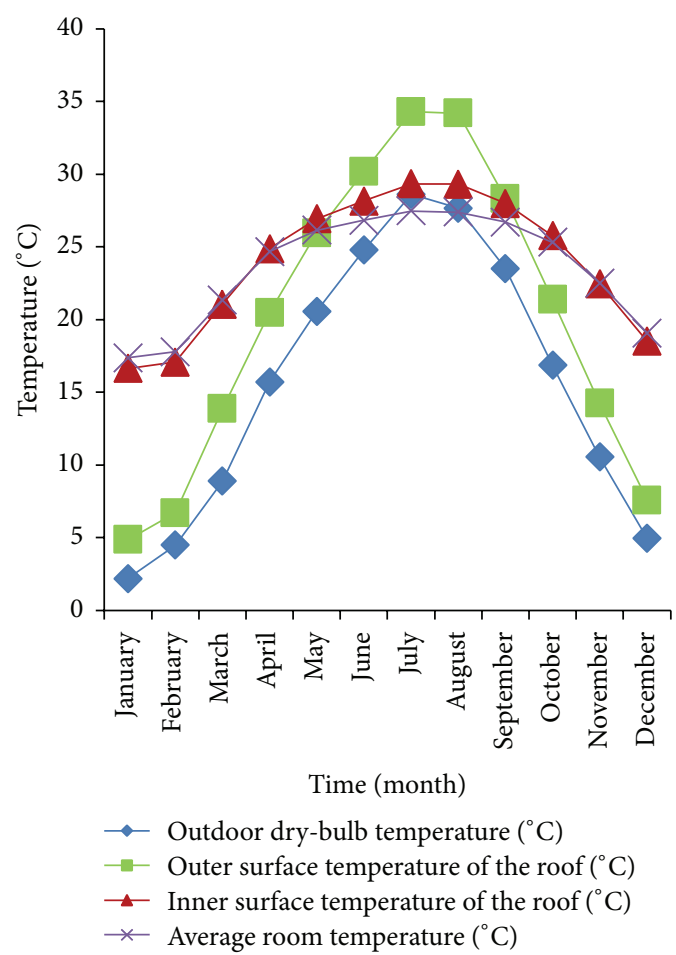

(a) Annual inner and outer surface temperatures for the regular house exposed to sunlight

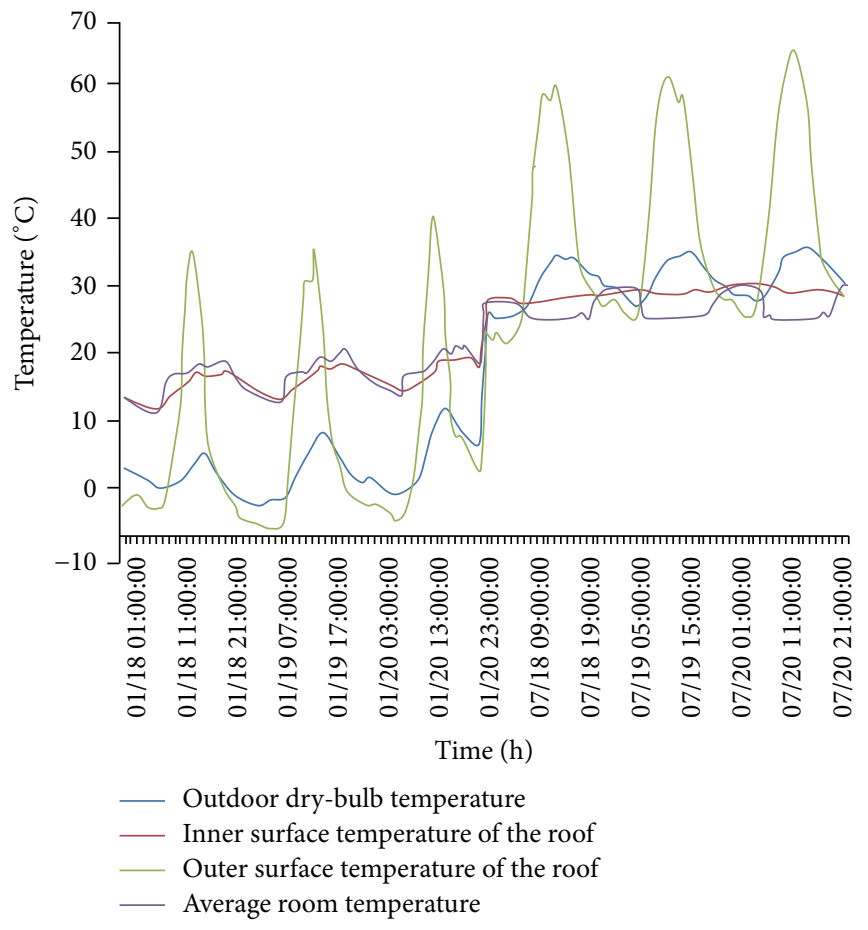

(b) Inner and outer surface temperatures for the regular house exposed to sunlight over a given period of time during the winter and summer

FIGURE 6: Simulated inner and outer surface temperatures for the regular house exposed to sunlight.

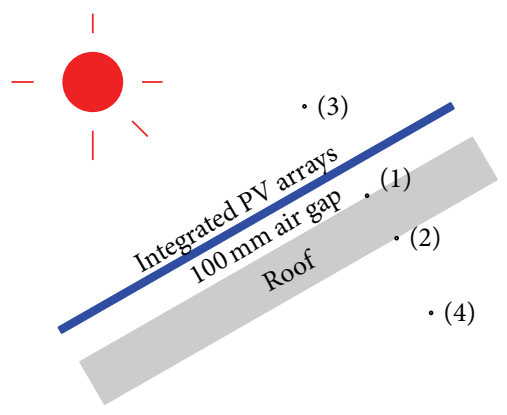

(1) Outer surface temperature of the roof

(2) Inner surface temperature of the roof

(3) Outdoor dry-bulb temperature

(4) Average room temperature

FIgURE 7: Temperature measurement points on the BIPV house.

point 3 in Figure 7). The simulated results did accurately reflect the actual effect of the thermal radiation from the back of the PV panels (when they were operated normally) on the outer surface temperature of the roof.

5.3. Roof Thermal Insulation Materials with an Infinite Thermal Conductivity. The outer surface temperature of the roof and the outdoor dry-bulb temperature were compared assuming that the thermal conductivity of the roof thermal insulation materials was infinite; that is, that the thermal resistance $(R)$ of the roof is $0 \mathrm{~m}^{2} \cdot \mathrm{K} / \mathrm{W}$.

When the thermal conductivity of the roof thermal insulation materials was infinite, the outer surface temperature of the south-facing integrated PV array-covered gable roof (measurement point 1 in Figure 7) was the same as the inner surface temperature but was lower than the outdoor dry-bulb temperature throughout the year. Therefore, in the EnergyPlus models, the PV panels blocked the incident solar radiation on the roof, and the thermal radiation from the back of the PV panels was not accurately reflected. Figure 10 shows that the average room and outdoor dry-bulb temperature trends were in agreement with actual values.

\section{Flat Plate Solar Collector Case}

We also simulated the effect of the thermal radiation from the back of the flat plate solar collectors on the outer surface temperature of the roof in Nanjing using EnergyPlus. In this case, although the solar collectors are fixed close to the outer surface of the roof, the air gap between solar collectors and roofs contains outdoor air, as shown in Figure 11. Figure 11 shows the inner and outer roof surface temperatures on which the flat plate solar collectors were installed. Figure 12 shows the effect that the flat plate solar collectors have on the outer surface temperature of the roof. 


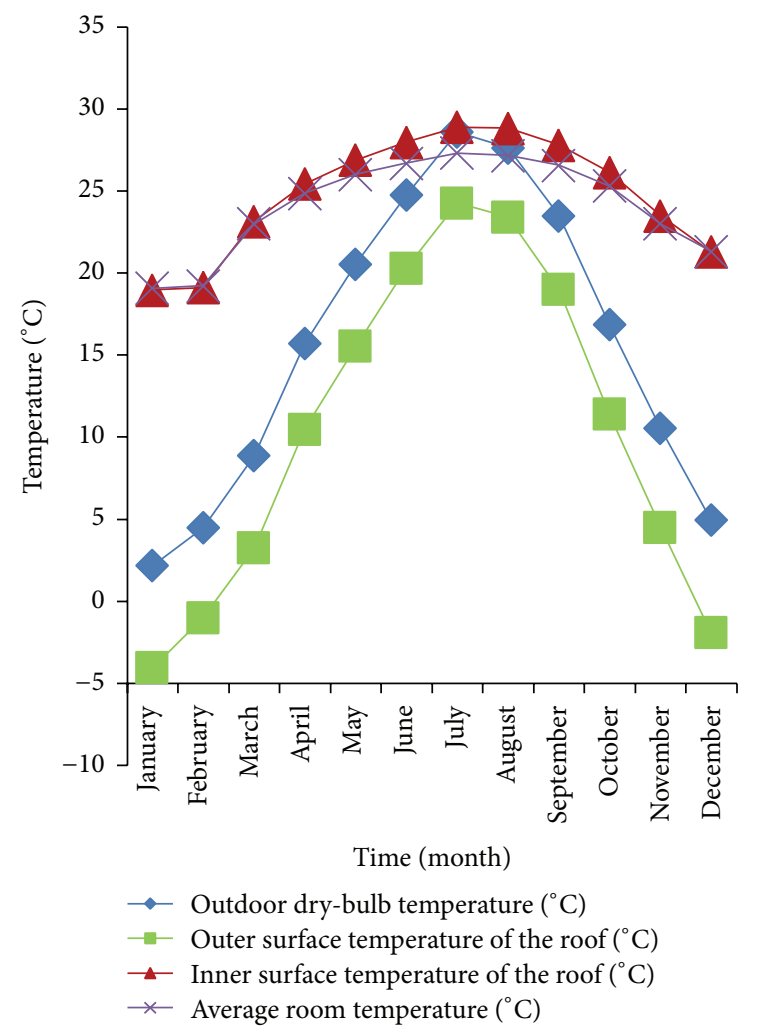

(a) Inner and outer surface temperatures for the BIPV house (roof $K=0)$

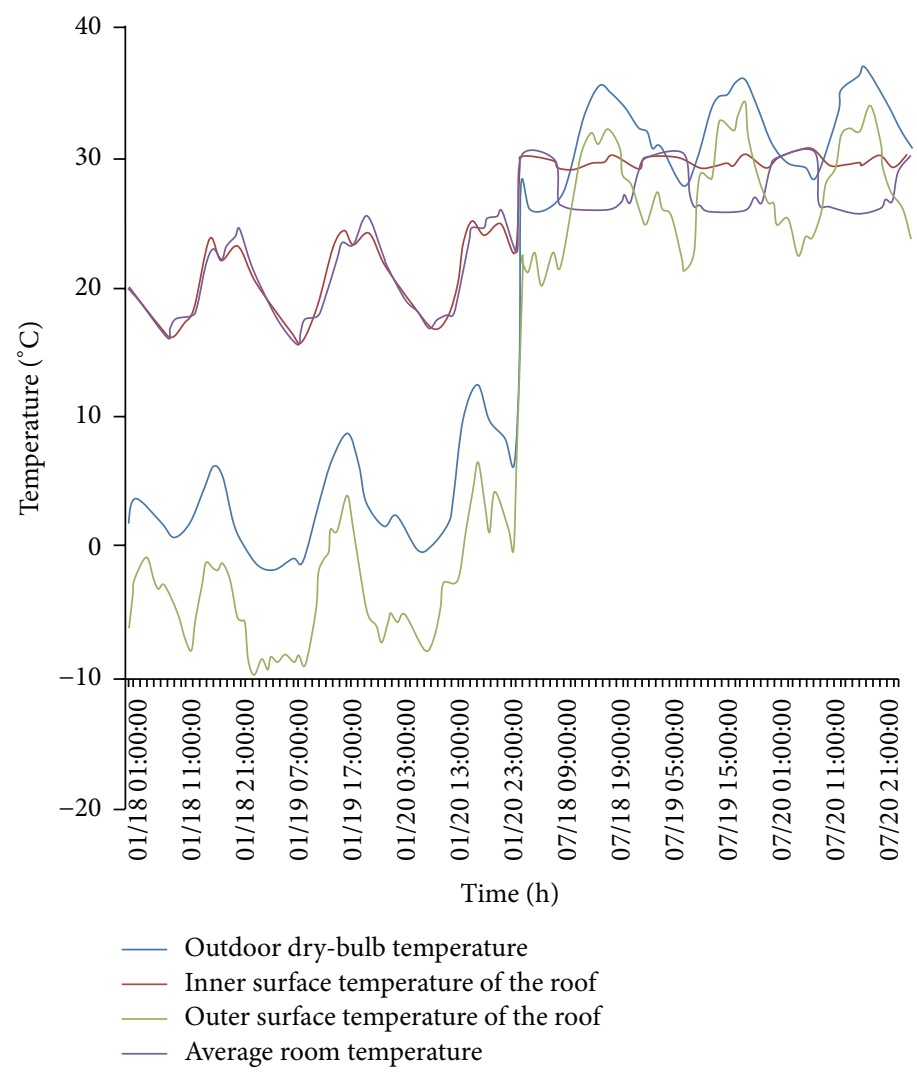

(b) Inner and outer surface temperatures for the BIPV house over a given period of time during winter and summer (roof $K=0$ )

FIGURE 8: Simulated inner and outer surface temperatures for the BIPV house (roof $K=0$ ).

Figure 12 shows that the outer surface temperature of the roof on which the flat plate solar collectors were installed (measurement point 1 in Figure 10) was always lower than the outdoor dry-bulb temperature. This result showed that EnergyPlus could not accurately simulate the effect that the thermal radiation from the back of the flat plate solar collectors had on the outer surface temperature of the roof.

\section{Different Climates}

Based on the PV array-covered roof model used in Section 5.2, the climate conditions were altered from a climate characterized by hot summers and cold winters, such as in Nanjing $\left(32^{\circ} \mathrm{N}\right.$ latitude), to a much cold climate, such as in Harbin $\left(45.8^{\circ} \mathrm{N}\right.$ latitude), or a climate described by hot summers and warm winters, such as in Haikou $\left(20^{\circ} \mathrm{N}\right.$ latitude). All of the other parameters used in the simulations remained the same. The simulated results are shown in Figures 13 and 14.

Figures 13 and 14 show that the outer surface temperatures on the south-facing integrated PV array-covered gable roof were lower than that for the outdoor dry-bulb temperature over the year, regardless of the climatic conditions. This result was the same as that in Nanjing.
The previously described results demonstrated that, with the exception of the additional power generation function, the PV panel models used in EnergyPlus cannot accurately simulate the thermal radiation originating from the back of the PV panels.

\section{Discussion}

Figures 4 and 6 show that EnergyPlus can accurately predict the roof surface temperature for the house without PV panels for the cases of both sunlight and no sunlight exposure.

However, Figures 8, 9, and 10 indicate that EnergyPlus encountered problems with accurately simulating the roof outer surface temperature for the house with PV panels and for thermal insulation material thermal conductivities of zero, normal, or infinite values.

Figure 12 also demonstrates that EnergyPlus cannot accurately simulate the effect that the thermal radiation from the back of the flat plate solar collectors has on the outer surface temperature of the roof.

Figures 13 and 14 show that a similar problem was observed for all of the different climates that were examined.

However, according to Griffith and Ellis [16], the BIPV "simple," "equivalent one-diode," and "Sandia" all allow 


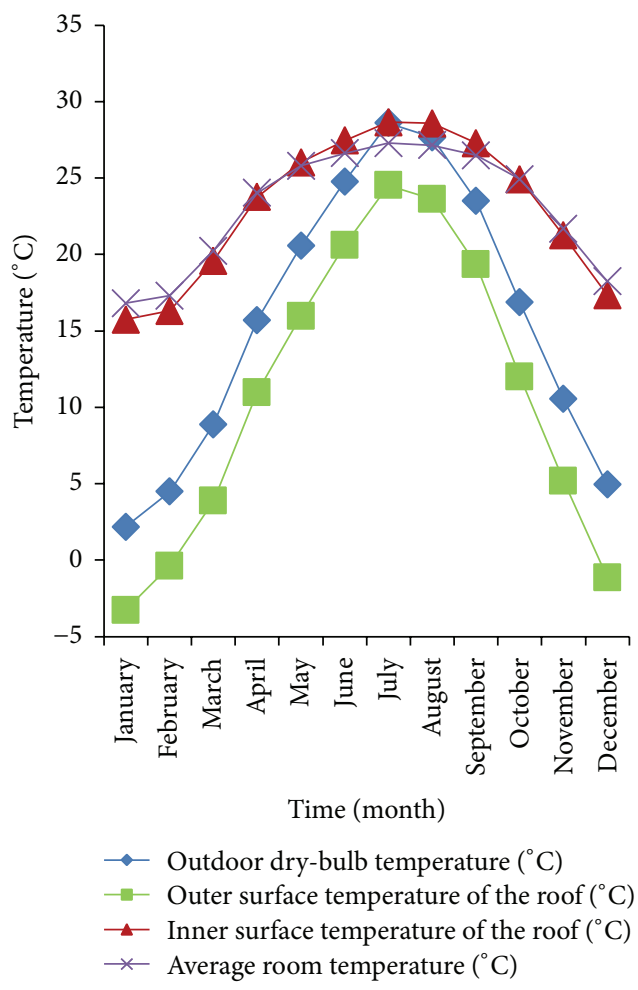

(a) Annual inner and outer surface temperatures for the BIPV house

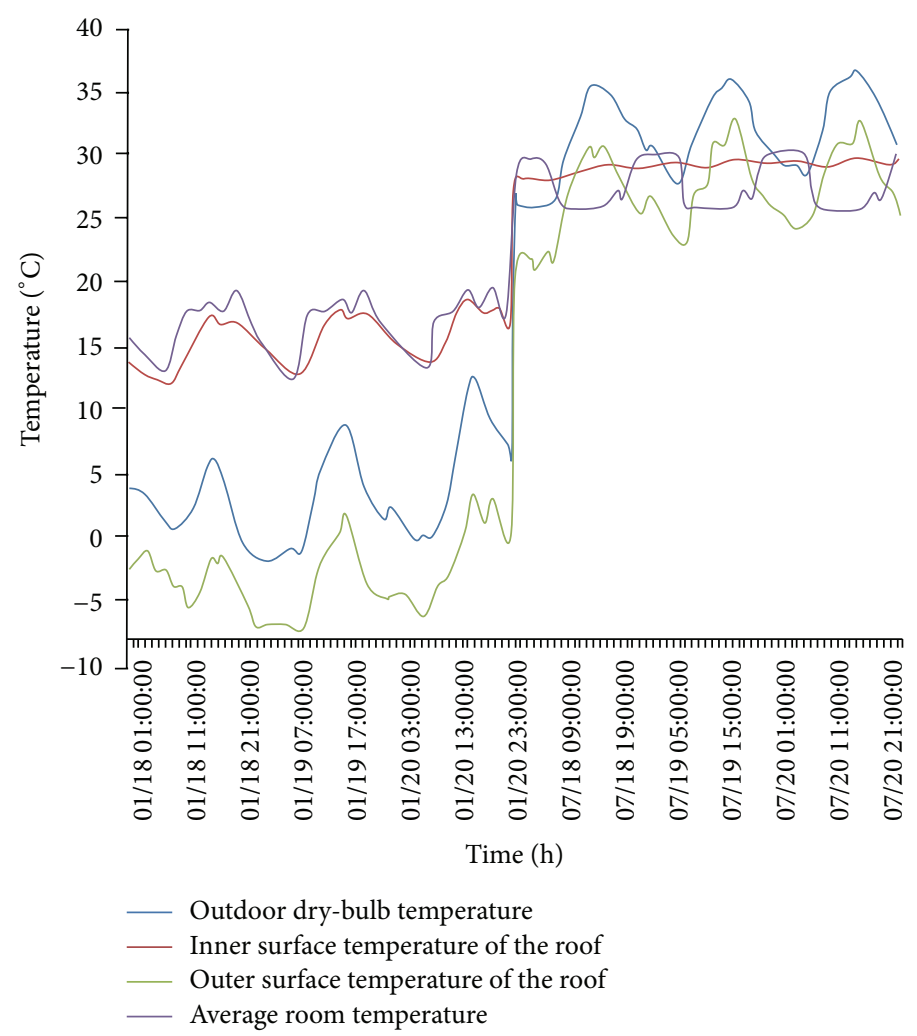

(b) Inner and outer surface temperatures for the BIPV house over a given period of time during the winter and summer

FIGURE 9: Simulated inner and outer surface temperatures for the BIPV house.

the PV modules to be colocated with the surfaces that form the building envelope in an EnergyPlus model. The "simple" and "Sandia" PV models can also model interactions with the exterior surface heat balance via the use of a source term that accounts for any energy exported in the form of electricity. The "equivalent one-diode" model does not presently interact with the surface heat balance. The "simple" model does not predict efficiency, and, therefore, it has no use for the surface temperature. However, the "Sandia" model is tightly coupled to the surface heat balance and uses the result for the exterior surface temperature as the back of the module temperature. A specific type of module was selected and modeled using Chicago weather data and a latitudeadjusted mounting angle. The results were found to agree within $5 \%$.

After carefully comparing the above module and our model, the root cause of the discrepancy was found in the model from Griffith and Ellis [16], in which the air gap between the PV panels and the building envelope was set as the "air conditioning zone." However, in this paper, this air gap could not be set as the "air conditioning zone" because it freely connected to the outdoor air to the cool PV panels to ensure that the panels generate power under normal conditions.

Therefore, heat transfer by convection, radiation, and conduction in the air gap between the PV panels and the building envelope, such as roofs and walls, can be simulated in the EnergyPlus environment when these air gaps are within the "air conditioning zone." Namely, the temperature and humidity of these air gaps can be controlled by the air conditioning equipment. However, in most cases, particularly on rooftops, the air gaps between the PV panels and the building envelope cannot be set as being within the "air conditioning zone," because these air gaps are typically freely connected to the outdoor air to cool PV panels and ensure that the panels generate power under normal conditions (we note that, for the connected area, a larger area is considered advantageous to promote better cooling). Hence, for this case, none of the three models can accurately simulate the effect that the PV panels have on the rooftop temperature in the EnergyPlus environment.

All of the terms in the Heat Balance Model, including the absorbed direct and diffuse solar radiation, net long-wave radiation with the air and surroundings, convective exchange with the outside air, and conduction flux inside or outside of the surface, may still be used to calculate the temperature and heat flux within BIPV's air gap. As an example, the Heat Balance Model is shown as follows for a ventilated air gap.

As mentioned in Figure 15, nodes $g, s$, and $t$ represent the glass cover of the PV module, the PV cell, and the PV back sheet, respectively. Node $f$ represents the air within the gap and node $d$ represents the roof. The variables $T_{e}$ and $T_{i}$ are 


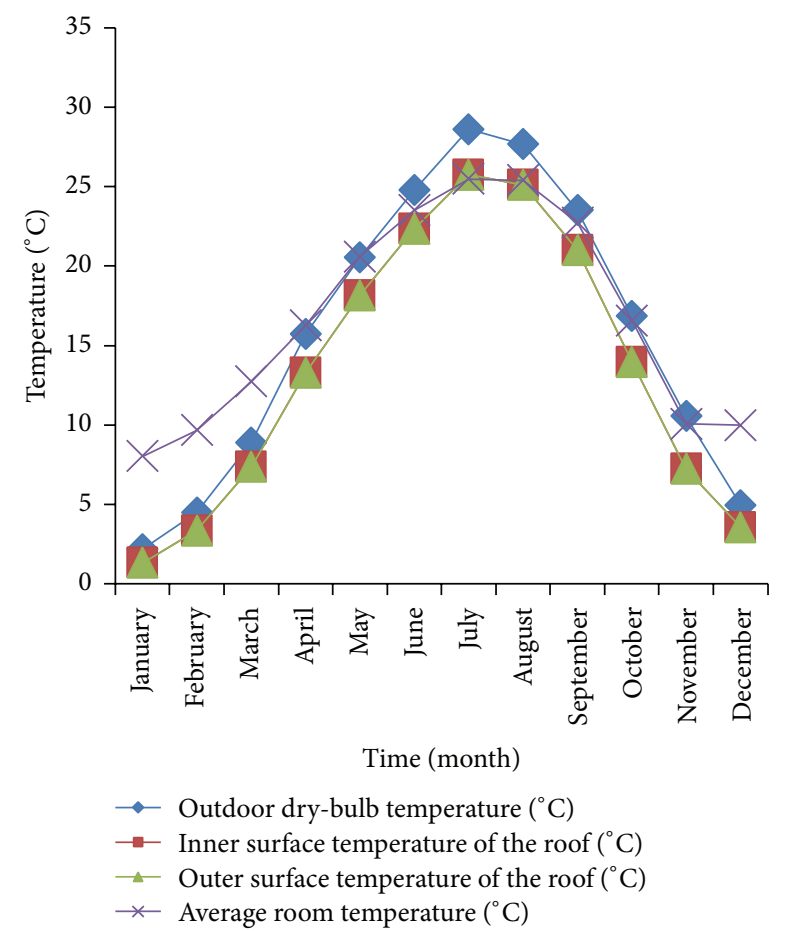

(a) Inner and outer surface temperatures for the BIPV house (roof $K=\infty)$

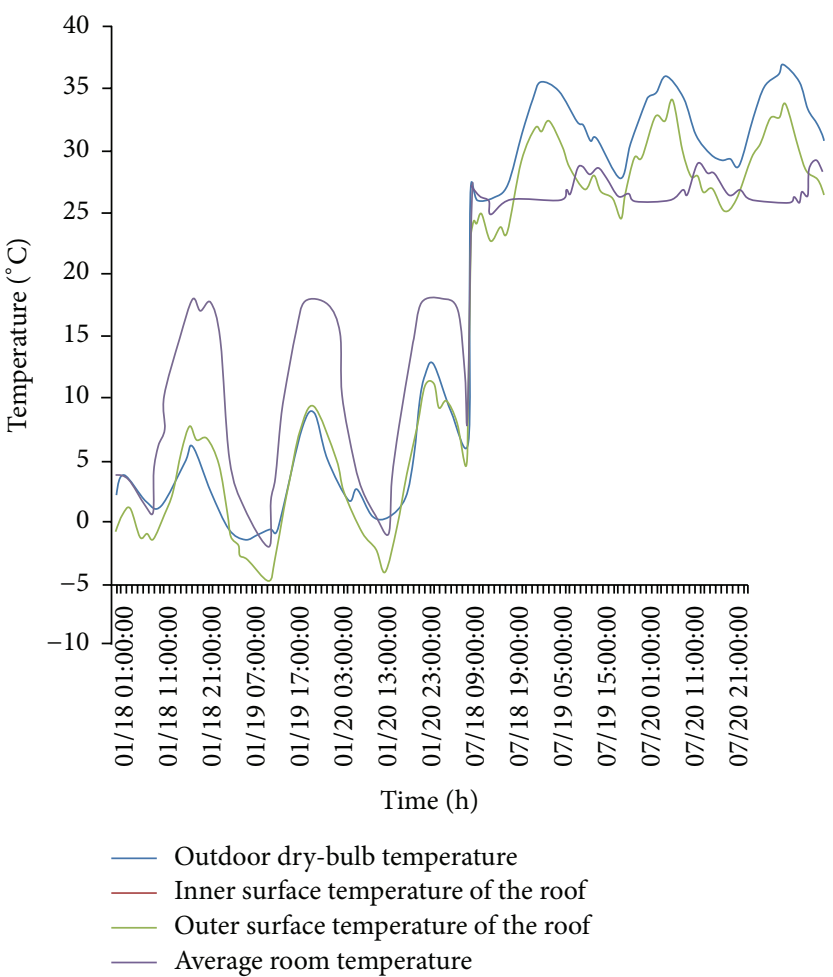

(b) Inner and outer surface temperatures for the BIPV house over a given period of time during the winter and summer ( $\operatorname{roof} K=\infty$ )

FIGURE 10: Simulated inner and outer surface temperatures for the BIPV house (roof $K=\infty$ ).

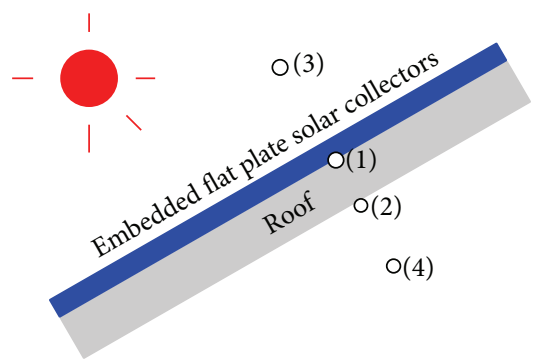

(1) Outer surface temperature of the roof

(2) Inner surface temperature of the roof

(3) Outdoor dry-bulb temperature

(4) Average room temperature

FIGURE 11: Roof temperature measurement points for the installed flat plate solar collectors.

the exterior and interior roof surface temperatures. Figure 16 illustrates the energy flow through the PV roof system with a ventilation gap based on an $R$-C circuit representation [13].

(1) For the Transparent Cover,

$$
\begin{aligned}
M_{g} C_{g} \frac{d T_{g}}{d t}= & G \alpha_{g} A\left(1-\rho_{o, g}\right)+h_{w} A\left(T_{a}-T_{g}\right) \\
& +h_{g s} A\left(T_{s}-T_{g}\right)+q_{r, g a},
\end{aligned}
$$

where the heat-transfer coefficient between the glass cover and the solar cells is

$$
h_{g s}=\frac{1}{\left(d_{g} / 2 / k_{g}+d_{s} / 2 / k_{s}\right)} .
$$

The convection coefficient due to the wind is given by [17]

$$
h_{w}=\sqrt{h_{n}^{2}+\left(2.38 V^{0.89}\right)^{2}} .
$$

The natural-convection component is described by

$$
h_{n}=9.482 \frac{\sqrt[3]{\left|T_{g}-T_{a}\right|}}{7.328-|\cos \theta|} .
$$

The longwave radiation portion $q_{r, g a}$ of the heat balance is split into the three parts, energy exchanged with the air, exchanged with the sky, and exchanged with the ground:

$$
\begin{aligned}
& q_{r, g a}=A \varepsilon_{g} \delta\left[F_{a}\left(T_{a}^{4}-T_{g}^{4}\right)+F_{\text {sky }}\left(T_{\text {sky }}^{4}-T_{g}^{4}\right)\right. \\
& \left.\quad+F_{\mathrm{gr}}\left(T_{\mathrm{gr}}^{4}-T_{g}^{4}\right)\right] .
\end{aligned}
$$

We assume that the surface ground temperature $T_{\mathrm{gr}}$ is equal to the air temperature $T_{a}$. The sky temperature is calculated as a function of the outdoor air temperature [17]:

$$
T_{\text {sky }}=0.0552\left(T_{a}+273.15\right)^{1.5} .
$$




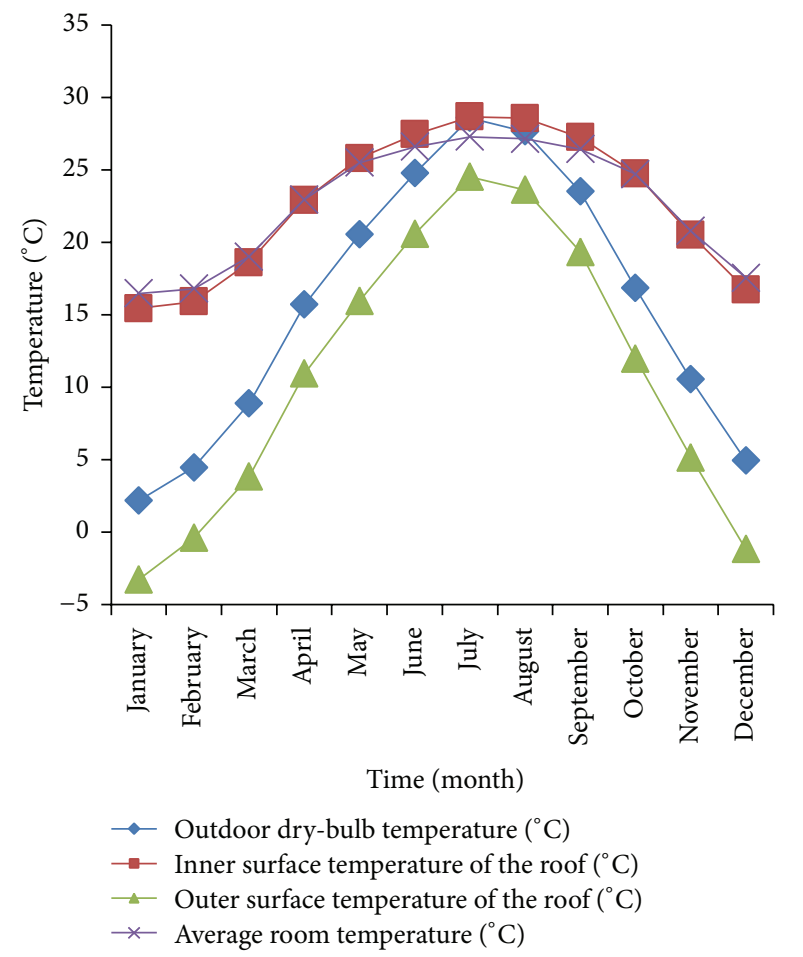

(a) Inner and outer surface temperatures for the gable roof on which flat plate solar collectors were installed

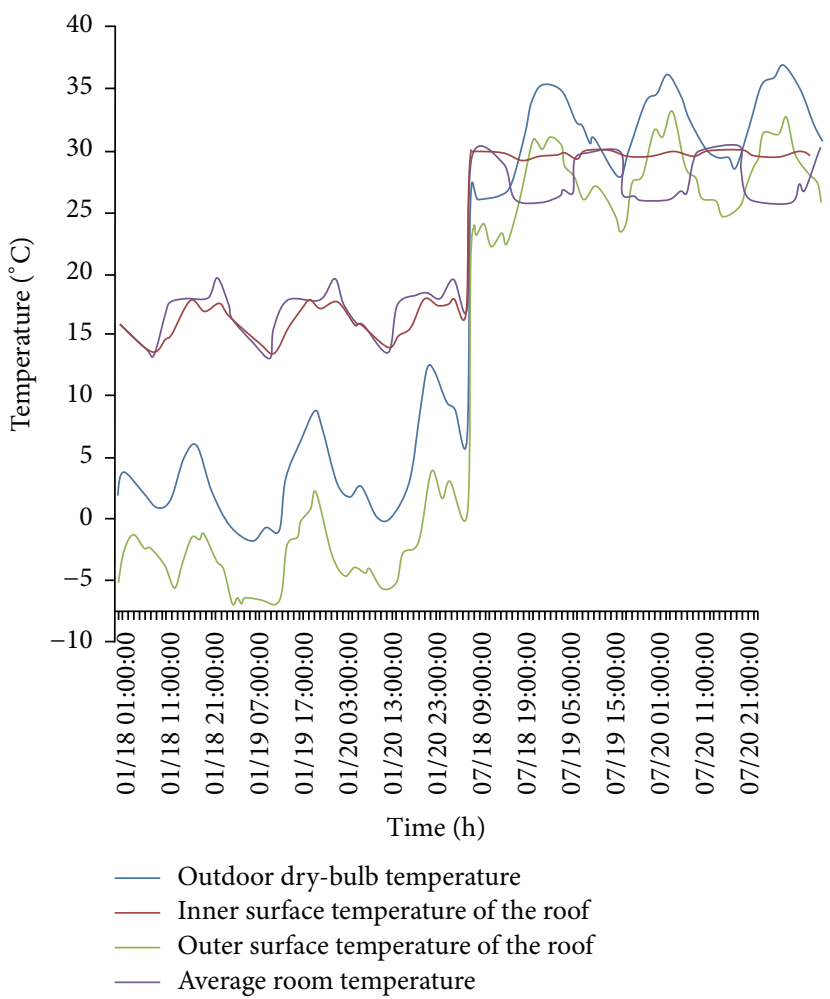

(b) Inner and outer surface temperatures for the gable roof on which flat plate solar collectors were installed over a given period of time during the winter and summer

FIGURE 12: Simulated inner and outer surface temperatures for the gable roof on which flat plate solar collectors were installed.

The calculation of the three view factors is based on the degree of PV tilt [18]:

$$
\begin{aligned}
F_{\text {sky }} & =\frac{1+\cos \theta}{2} \cos \left(\frac{\theta}{2}\right), \\
F_{\mathrm{gr}} & =\frac{1-\cos \theta}{2}, \\
F_{a} & =1-F_{\text {sky }}-F_{\mathrm{gr} .}
\end{aligned}
$$

\section{(2) For the Solar Cells,}

$$
\begin{aligned}
M_{s} C_{s} \frac{d T_{s}}{d t}= & G\left(1-\rho_{o, g}\right)\left(1-\alpha_{g}\right) \alpha_{s}+h_{s t} A\left(T_{t}-T_{s}\right) \\
& +h_{g s} A\left(T_{g}-T_{s}\right)-P_{m p} .
\end{aligned}
$$

The heat-transfer coefficient between the solar cells and the back sheet of the PV is given by

$$
h_{s t}=\frac{1}{\left(d_{t} / 2 / k_{t}+d_{s} / 2 / k_{s}\right)} \text {. }
$$

(3) For the Back Sheet of the PV,

$$
\begin{aligned}
M_{t} C_{t} \frac{d T_{t}}{d t}= & h_{s t} A\left(T_{s}-T_{t}\right)+h_{t f} A\left(T_{f}-T_{t}\right) \\
& +\frac{A \delta\left(T_{e}^{4}-T_{t}^{4}\right)}{\left(1 / \varepsilon_{t}+1 / \varepsilon_{e}-1\right)} .
\end{aligned}
$$

The convective heat-transfer coefficient between the PV rear plate and the air within the gap may be obtained from [19]

$$
h_{t f}=\frac{\mathrm{Nu} k_{f}}{D_{h}}=\left(5.801+0.086 \operatorname{Re} \frac{D_{h}}{L}\right) \frac{k_{f}}{D_{h}} .
$$

(4) For the Heat Transfer and Airflow within the Gap,

$$
\begin{aligned}
M_{f} C_{f} \frac{d T_{f}}{d t}= & h_{f e} A\left(T_{e}-T_{f}\right)+h_{t f} A\left(T_{t}-T_{f}\right) \\
& -m_{f} C_{f}\left(T_{f o}-T_{f i}\right) .
\end{aligned}
$$

We assume that the convective heat-transfer coefficient $h_{t f}$ on the rear plate of the PV is equal to $h_{f e}$ on the roof's exterior surface. Assuming a linear heat increase within the air gap,

$$
T_{f}=\frac{\left(T_{f o}+T_{f i}\right)}{2} .
$$




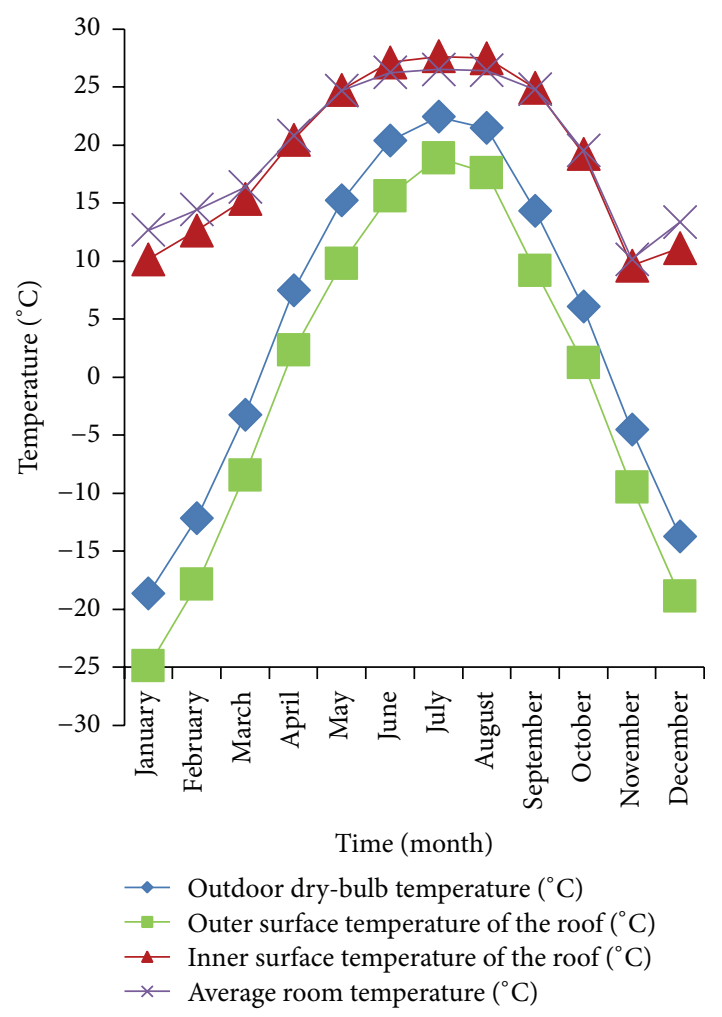

(a) Inner and outer surface temperatures for the BIPV house in Harbin

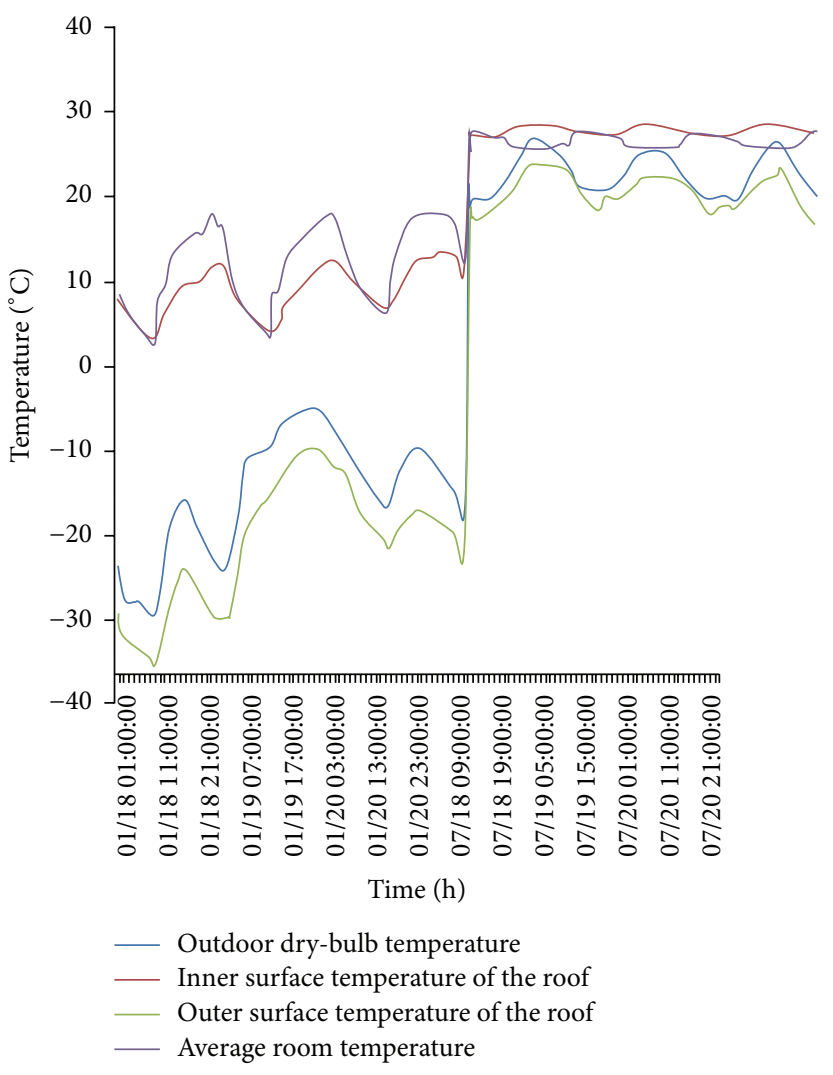

(b) Inner and outer surface temperatures for the BIPV house over a given period of time during the winter and summer in Harbin

FIGURE 13: Simulated inner and outer surface temperatures for the BIPV house in Harbin.

The airflow rate in the gap caused by buoyancy and wind pressure is given by [20]

$$
m_{f}=\rho_{f} A_{c} \sqrt{\frac{2 \beta\left(T_{f o}-T_{f i}\right) L g \sin \theta+C_{p} V}{K_{f 1}+K_{f 2}+f L / D_{h}}} \frac{\left(T_{f o}+T_{f i}\right)}{2},
$$

where $V$ is the wind speed, $K_{f 1}$ and $K_{f 2}$ are the inlet and outlet pressure-loss coefficients, and $C_{p}$ is the windpressure coefficient. An average value of 0.25 is taken from the literature [20].

The air has a mass flow rate of $m_{f}$, enters the air duct at temperature $T_{f}$, which is approximately equal to the ambient air temperature, and leaves with a higher temperature $T_{f o}$.

For the roof heat transfer, we assume that the heat transfer through the roof is one-dimensional unsteady heatconduction, as defined by

$$
\frac{\partial T}{\partial t}=\alpha_{d} \frac{\partial^{2} T}{\partial x^{2}} .
$$

The boundary conditions used for (15) are defined by the following expressions:

$$
-\left.k_{d} \frac{\partial T}{\partial x}\right|_{x=0}=h_{f e}\left(T_{e}-T_{f}\right)+\frac{\delta\left(T_{e}^{4}-T_{t}^{4}\right)}{\left(1 / \varepsilon_{t}+1 / \varepsilon_{e}-1\right)},
$$

$$
-\left.k_{d} \frac{\partial T}{\partial x}\right|_{x=d_{d}}=h_{i h}\left(T_{i}-T_{h}\right) .
$$

The indoor space is characterized by a specified internal temperature $T_{h}=24^{\circ} \mathrm{C}$ and is coupled to the interior surface by a heat-transfer coefficient [21].

(5) Model of the PV Roof with a Nonventilated (Closed) Air Gap. The equations for the PV roof with a closed air gap are largely the same as for the PV roof with a ventilated air gap. The differences are the absence of the third term in (12). The convective heat-transfer coefficient on the PV back sheet and the exterior surface of the roof are determined by [22]

$\mathrm{Nu}$

$$
\begin{aligned}
& =1 \\
& \quad+1.44\left[1-\frac{1708}{R_{a} \cos \theta}\right]\left\{1-\frac{1708(\sin 1.8 \theta)^{1.6}}{R_{a} \cos \theta}\right\} \\
& \quad+\left[\left(\frac{R_{a} \cos \theta}{5830}\right)^{1 / 3}\right]-1,
\end{aligned}
$$

where the term in the square brackets is set to zero if the quantity within the brackets is negative. 


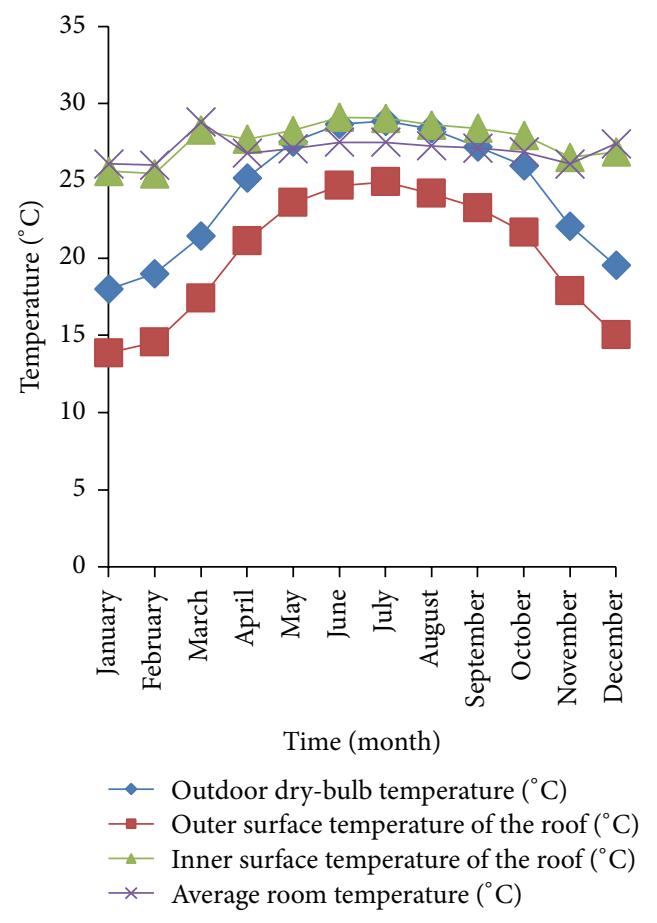

(a) Inner and outer surface temperatures for the BIPV house in Haikou

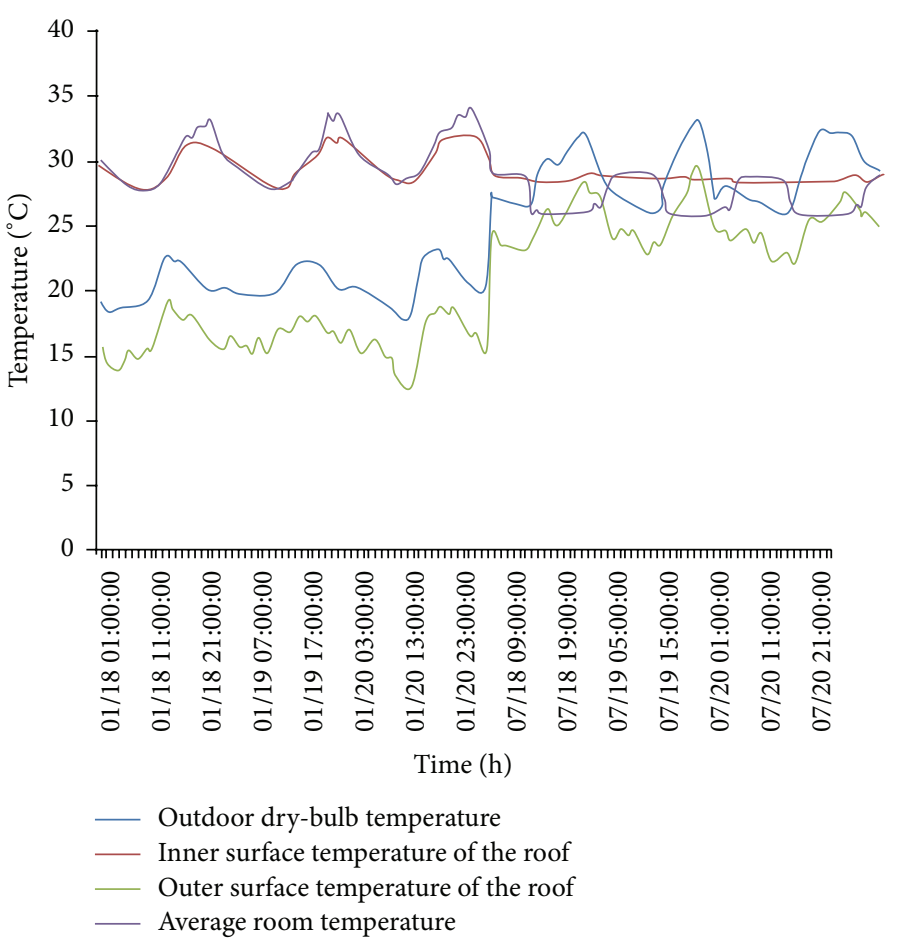

(b) Inner and outer surface temperatures for the BIPV house over a given period of time during the winter and summer in Haikou

FIGURE 14: Simulated inner and outer surface temperatures for the BIPV house in Haikou.

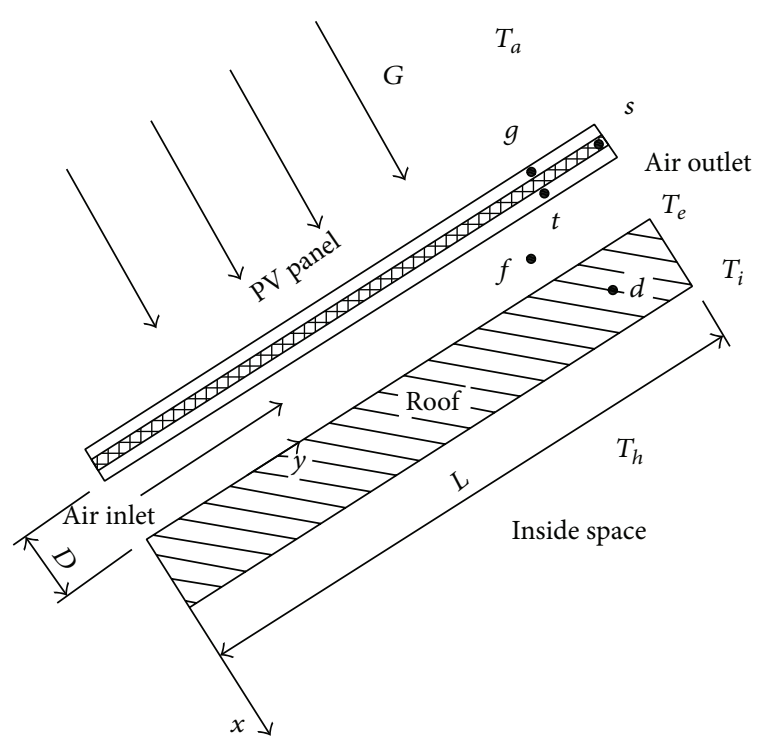

FIGURE 15: Model of the ventilated air gap in the BIPV.

\section{Conclusions}

EnergyPlus is a whole-building energy simulation program that engineers, architects, and researchers use to model energy and water use in buildings. Currently, there are three models that may be used to predict PV electricity generation

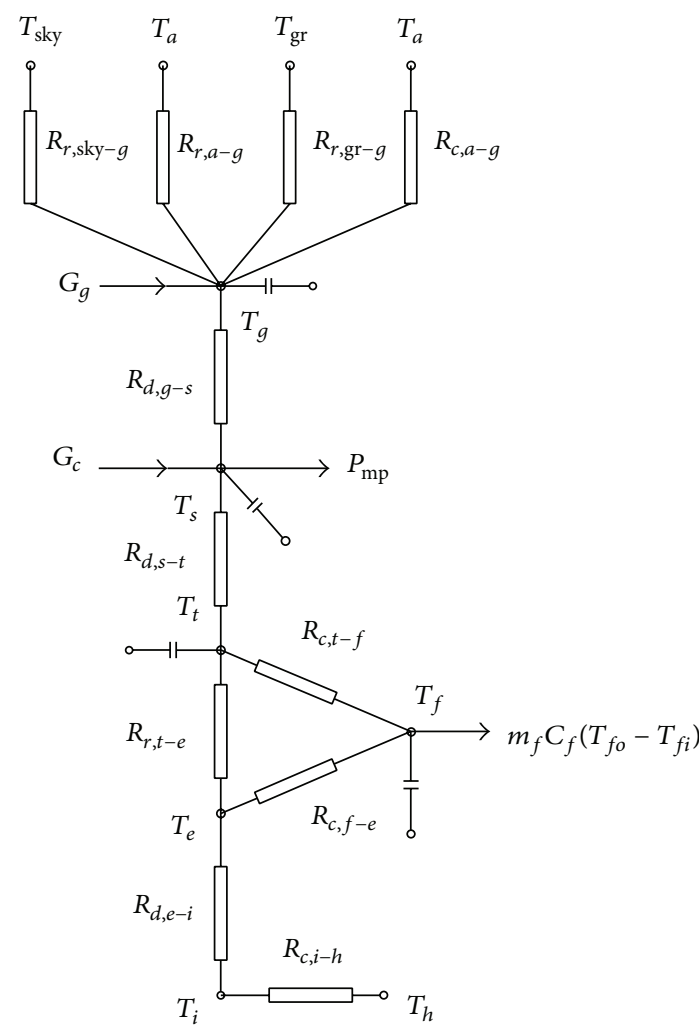

FIgURE 16: The $R-C$ circuit used to model the ventilated air gap within the BIPV. 
capacity: the "simple" model, the "equivalent one-diode" model, and the "Sandia" model.

In this paper, the effects that the PV panels have on the rooftop temperature in the EnergyPlus simulation environment were investigated for the following cases: with and without PV panels, with and without exposure to sunlight, and using roof materials with different thermal conductivities and for different climatic zones. The results show that heat transfer by convection, radiation, and conduction in the air gap between the PV panels and the building envelope, such as roofs and walls, can be simulated in the EnergyPlus environment when these air gaps are within the "air conditioning zone." Nevertheless, in most cases, particularly for rooftops, the air gaps between the PV panels and the building envelope cannot be set as the "air conditioning zone" because they are typically freely connected to the outdoor air to cool the PV panels to ensure that they generate power under normal conditions. Therefore, for this case, none of the three models can accurately simulate the effect that the PV panels have on rooftop temperature in the EnergyPlus environment.

However, all the terms in the Heat Balance Model, including the absorbed direct and diffuse solar radiation, net longwave radiation with the air and surroundings, convective exchange with the outside air, and conduction flux in or out of the surface, can still be used to calculate the temperature and heat flux within BIPV's air gap.

\section{Conflict of Interests}

The authors declare that there is no conflict of interests regarding the publication of this paper.

\section{Acknowledgments}

The authors would like to acknowledge the support of the National Natural Science Foundation of China (51278107), the China Scholarship Council (201406095032), the Key Program of the Natural Science Foundation of Jiangsu Province (BK2010061), the R\&D Program of the Ministry of Housing and Urban-Rural Development of the People's Republic of China (2011-K1-2), the Open Project Program of the Key Laboratory of Urban and Architectural Heritage Conservation (Southeast University), and the Ministry of Education (KLUAHC1212).

\section{References}

[1] EnergyPlus, EnergyPlus Engineering Reference: The Reference to EnergyPlus Calculations, The Board of Trustees of the University of Illinois, Regents of the University of California through the Ernst Orlando Lawrence Berkley National Laboratory, 2013.

[2] S. Pless, B. Talbert, M. Deru, and P. Torcellini, Energy Design Analysis and Evaluation of a Proposed Air Rescue and Fire Fighting Administration Building for Teterboro Airport, National Renewable Energy Laboratory, Golden, Colo, USA, 2003.

[3] M. Ordenes, D. L. Marinoski, P. Braun, and R. Rüther, "The impact of building-integrated photovoltaics on the energy demand of multi-family dwellings in Brazil," Energy and Buildings, vol. 39, no. 6, pp. 629-642, 2007.
[4] C. Hachem, A. Athienitis, and P. Fazio, "Investigation of solar potential of housing units in different neighborhood designs," Energy and Buildings, vol. 43, no. 9, pp. 2262-2273, 2011.

[5] O. Zogou and H. Stapountzis, "Energy analysis of an improved concept of integrated PV panels in an office building in central Greece," Applied Energy, vol. 88, no. 3, pp. 853-866, 2011.

[6] P. Gang, F. Huide, J. Jie, C. Tin-Tai, and Z. Tao, "Annual analysis of heat pipe $\mathrm{PV} / \mathrm{T}$ systems for domestic hot water and electricity production," Energy Conversion and Management, vol. 56, pp. 8-21, 2012.

[7] M. Mandalaki, K. Zervas, T. Tsoutsos, and A. Vazakas, "Assessment of fixed shading devices with integrated PV for efficient energy use," Solar Energy, vol. 86, no. 9, pp. 2561-2575, 2012.

[8] M. Mandalaki, S. Papantoniou, and T. Tsoutsos, "Assessment of energy production from photovoltaic modules integrated in typical shading devices," Sustainable Cities and Society, vol. 10, pp. 222-231, 2014.

[9] P. K. Ng, N. Mithraratne, and H. W. Kua, "Energy analysis of semi-transparent BIPV in Singapore buildings," Energy and Buildings, vol. 66, pp. 274-281, 2013.

[10] C.-M. Hsieh, Y.-A. Chen, H. Tan, and P.-F. Lo, "Potential for installing photovoltaic systems on vertical and horizontal building surfaces in urban areas," Solar Energy, vol. 93, pp. 312321, 2013.

[11] Itron, CPUC California Solar Initiative 2009 Impact Evaluation, 2010, http://www.cpuc.ca.gov/NR/rdonlyres/70B3F447-ADF548D3-8DF0-5DCE0E9DD09E/0/2009_CSI_Impact_Report.pdf.

[12] H. X. Yang, J. Burnett, Z. Zhu, and L. Lu, "A simulation study on the energy performance of photovoltaic roofs," ASHRAE Transactions, vol. 107, pp. 129-135, 2001.

[13] Y. Wang, W. Tian, J. Ren, L. Zhu, and Q. Wang, "Influence of a building's integrated-photovoltaics on heating and cooling loads," Applied Energy, vol. 83, no. 9, pp. 989-1003, 2006.

[14] W. Tian, Y. Wang, Y. Xie, D. Wu, L. Zhu, and J. Ren, "Effect of building integrated photovoltaics on microclimate of urban canopy layer," Building and Environment, vol. 42, no. 5, pp. 18911901, 2007.

[15] A. Dominguez, J. Kleissl, and J. C. Luvall, "Effects of solar photovoltaic panels on roof heat transfer," Solar Energy, vol. 85, no. 9, pp. 2244-2255, 2011.

[16] B. T. Griffith and P. G. Ellis, Photovoltaic and Solar Thermal Modeling with the EnergyPlus Calculation Engine, Center for Buildings and Thermal Systems, National Renewable Energy Laboratory, Golden, Colo, USA, 2004, http://gundog.lbl.gov/ dirpubs/bg_36275.pdf.

[17] J. A. Duffie and W. A. Beckman, Solar Engineering of Thermal Processes, John Wiley \& Sons, New York, NY, USA, 1980.

[18] T. M. McClellan and C. O. Pedersen, "Investigation of outside heat-balance models for use in a heat-balance cooling load calculation procedure," ASHRAE Transactions, vol. 103, no. 2, pp. 469-484, 1997.

[19] B. J. Brinkworth, R. H. Marshall, and Z. Ibarahim, "A validated model of naturally ventilated PV cladding," Solar Energy, vol. 69, no. 1, pp. 67-81, 2000.

[20] C. Afonso and A. Oliveira, "Solar chimneys: simulation and experiment," Energy and Buildings, vol. 32, no. 1, pp. 71-79, 2000.

[21] ASHRAE, ASHRAE Handbook-Fundamentals, American Society of Heating, Refrigerating and Air-Conditioning Engineers, Atlanta, Ga, USA, 2001.

[22] K. G. T. Hollands, T. E. Unny, G. D. Raithby, and L. Konicek, "Free convective heat transfer across inclined air layers," Journal of Heat Transfer, vol. 98, no. 2, pp. 189-193, 1976. 

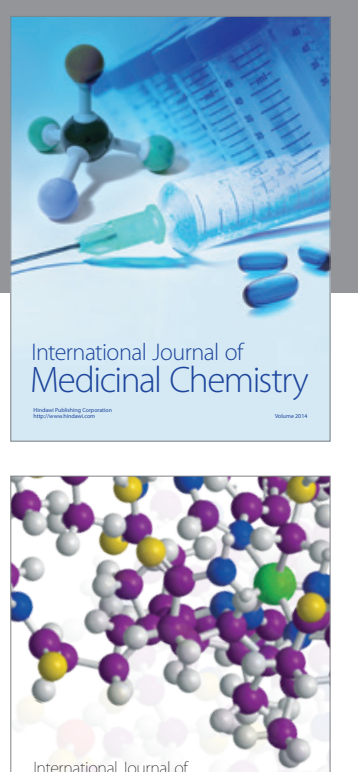

Carbohydrate Chemistry

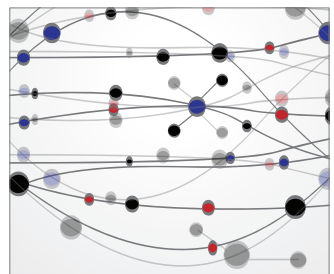

The Scientific World Journal
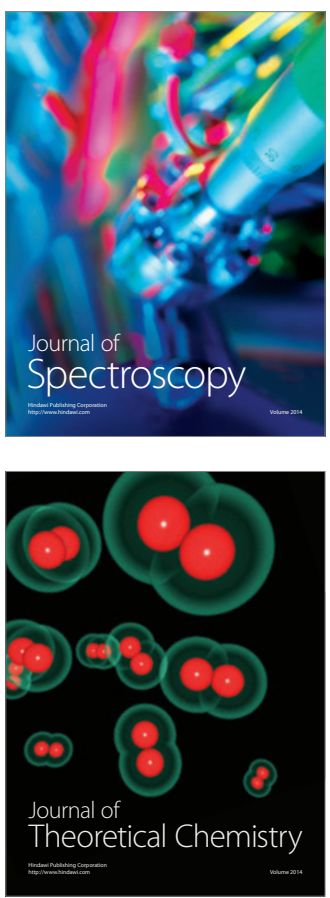
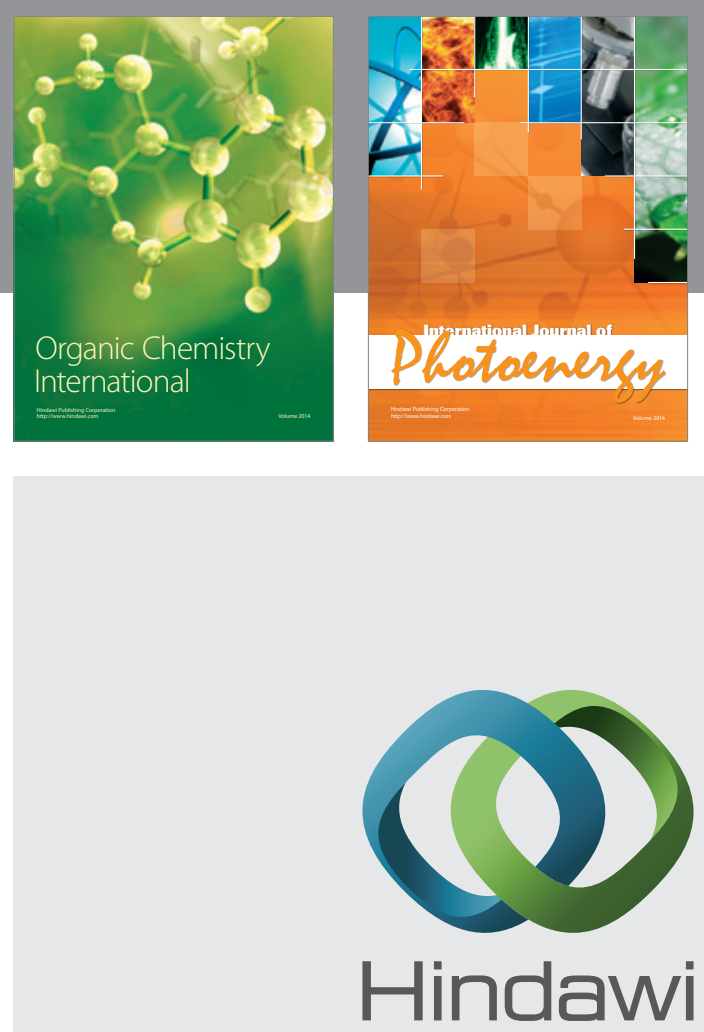

Submit your manuscripts at

http://www.hindawi.com

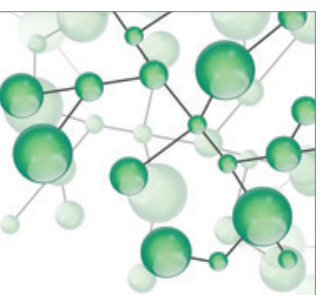

International Journal of

Inorganic Chemistry

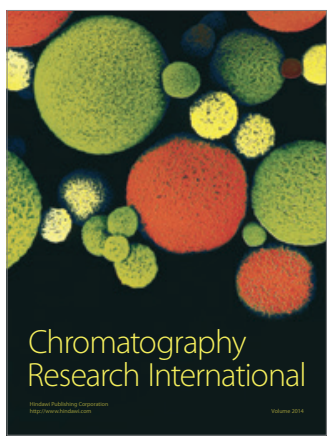

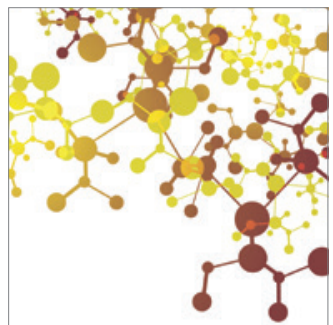

Applied Chemistry
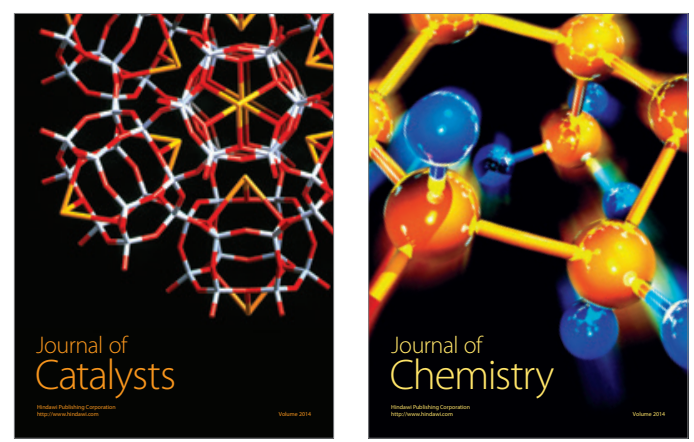
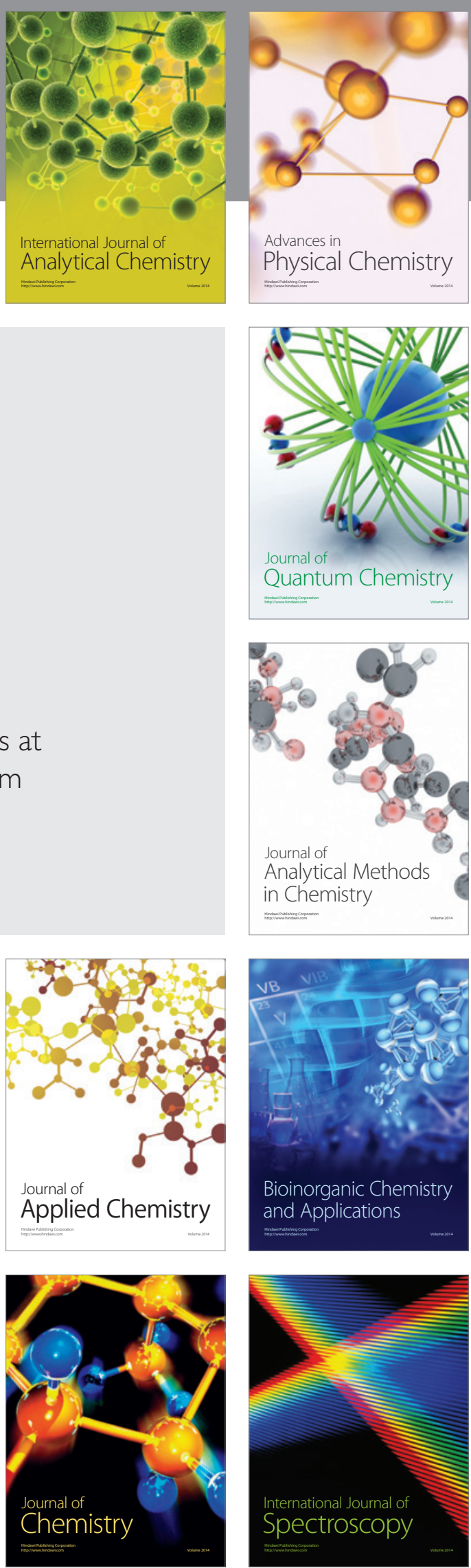